\title{
Rubella reinfection
}

Maternal rubella infection during pregnancy can have a devastating effect on the fetus. Congenital defects, frequently multiple, occur in up to $90 \%$ of infants whose mothers are infected during the first 10 weeks of gestation. ${ }^{1}$ After 10 weeks, sensorineural deafness is often the only manifestation of intrauterine infection but is usually bilateral and sufficiently severe for the child to need education at a special school. ${ }^{2}$ Until rubella vaccine was licensed in 1969 , the only way of preventing congenital rubella was by offering termination of pregnancy when maternal infection was diagnosed. Unfortunately the availability of a safe and effective vaccine has not solved the problem. Nearly 1000 children with congenital rubella have been notified to the National Congenital Rubella Surveillance Programme (NCRSP) since 1970. These children are only a proportion of the actual number affected as many of those with sensorineural deafness as a single defect are not diagnosed as having congenital rubella unless there is a maternal history of rubella in pregnancy. ${ }^{3}$

Many of the children reported to the NCRSP were born before the UK selective vaccination programme had begun to reduce rubella susceptibility in the antenatal population. In $1986 / 7$, however, when only $2-3 \%$ of pregnant women remained susceptible, ${ }^{45}$ over 60 congenitally infected children were notified to the registry ( $G$ Jones, personal communication). Clearly, as long as rubella virus circulates in the population, infection of non-immune women is inevitable. The aim of the measles-mumps-rubella vaccination programme introduced in October 1988 is to interrupt transmission of rubella among children and thereby protect susceptible pregnant women from infection. It will be some years before this is achieved, however, and exposure of pregnant women to rubella will continue for the immediate future.

Inevitably the serological investigation of pregnant contacts will identify some cases of asymptomatic reinfection among women who have been reported positive to rubella antibody in the past. Until recently, maternal reinfection was not thought to present a significant risk to the fetus. There have now been a number of reports of congenital rubella after maternal reinfection, however, ${ }^{6-8}$ suggesting that the risk may be higher than previously supposed, particularly among women with vaccine induced immunity. ${ }^{9}$ As the proportion of the antenatal population with vaccine induced immunity is growing, is rubella reinfection likely to emerge as a significant clinical problem during the next few years?

\section{The incidence of reinfection}

Studies carried out over 20 years ago established that neither a primary attack of rubella nor successful immunisation always conferred lifelong immunity and that further infections (reinfections) could occur. Reinfections were characteristically subclinical but could be diagnosed by demonstrating a significant rise in rubella antibody titre. Investigation of antibody positive individuals exposed to rubella during outbreaks showed that over $50 \%$ of contacts with vaccine induced immunity experienced reinfection compared with only $5 \%$ of those with natural immunity. ${ }^{10} 11$ Subsequent studies showed that reinfection was most likely in women whose antibody titres had declined to a low level since vaccination. ${ }^{12}$

Since the first cohorts of girls vaccinated at school are now over 30 years of age, a substantial proportion of the current antenatal population has vaccine induced immunity. The true incidence of reinfection in pregnancy is not known but judging from reports to the Communicable Disease Surveillance Centre (CDSC) from laboratories in England and Wales, reinfection may now be as common as primary infection. From July 1988 to June 1989 a total of 101 confirmed infections in pregnancy were reported, of which 35 were probable reinfections. As reinfections are asymptomatic, they only come to light when investigating pregnant women who report contact with rubella. The number of cases diagnosed in the laboratory therefore represent only a proportion of the actual number occurring in the antenatal population.

\section{Risk to the fetus of maternal reinfection}

The number of well documented cases of fetal infection arising from maternal reinfection are still relatively few, confirming that the risk to the fetus is substantially lower than that after a primary infection. The absence of any documented cases of congenital rubella in siblings other than twins supports this conclusion. However, the precise degree of risk can only be estimated from the results of prospective studies of the outcome of reinfection in pregnancy. Two such studies have so far been reported ${ }^{13}{ }^{14}$; these found no cases of fetal infection among a total of 41 pregnancies that continued to term. Although this result is reassuring, the numbers followed up are small particularly among women whose initial immunity was vaccine induced as only five of the 41 cases above were in confirmed vaccinees.

To defined the risk of reinfection in pregnancy more accurately a prospective study had been set up by the Public Health Laboratory Service. Obstetricians caring for patients in whom reinfection has been diagnosed are asked to send cord blood samples to CDSC for specific IgM antibody testing. Evidence of congenital infection will also be sought by testing infants for the persistance of IgG antibody after a year, providing that the blood sample is taken before measles-mumps-rubella vaccine is given.

\section{Criteria for defining reinfection}

Distinguishing between primary asymptomatic rubella infection and reinfection is critically important when a woman is in the early stages of pregnancy. Providing appropriate sera are taken, the distinction can usually be made on the basis of the serological response at the time of infection. In both primary infection and reinfection there is a significant rise in rubella specific IgG antibody, but in a primary infection there is also a strong IgM antibody response which persists for about six to eight weeks; in a reinfection IgM antibody is either not produced or found only in low concentrations. Thus reinfection can be confidently diagnosed if the initial sample taken from a contact is IgG antibody positive and a rise in titre is subsequently demonstrated with a negative or low level IgM response.

In cases which present late, however, the initial sample may not be taken until some weeks after the infection. Under these circumstances, the serological evidence may be ambiguous and the diagnosis of reinfection must rely on evidence of pre-existing rubella antibody. If serum samples taken before pregnancy are not available for retesting, laboratory reports of two or more previous positive rubella antibody tests by a method such as radial haemolysis (which does not give false positive results) are adequate evidence of 
pre-existing antibody. A single positive laboratory report must be treated with scepticism because of the possibility of earlier technical or clerical error. A documented history of rubella vaccination followed by one positive test is acceptable evidence of pre-existing antibody, however, because the possibility of vaccine failure combined with laboratory error is remote.

The same criteria for evidence of pre-existing antibody should also apply when attributing congenital rubella infection to maternal reinfection. Twelve such cases have recently been reported in the $\mathrm{UK}^{6-8}$ (G Jones, personal communication); in nine the mother had been tested and found positive at least twice before the affected pregnancy and in the remaining three there was a documented history of rubella vaccination followed by one positive antibody test.

\section{Clinical management of the problem}

Because of the growing number of well documented cases of congenital rubella after maternal reinfection, pregnant contacts who have been reported rubella antibody positive in the past can no longer be reassured that their fetus is not at risk. Serological investigation of all pregnant contacts irrespective of rubella antibody or vaccination history must therefore be considered. However, if reinfection is diagnosed, what advice can be given to the parents?

From the results of the two prospective studies so far carried out, it is likely that the risk of fetal infection is below $10 \%$ and probably less than $5 \%$, although in women with vaccine induced immunity the risk may be higher than this. A reliable method of antenatal diagnosis of congenital infection would be of enormous value in clinical management but unfortunately none of the methods currently available is satisfactory. Testing fetal blood for rubella specific IgM antibody can only be done relatively late as the fetus may not produce IgM until after the 23 rd week despite maternal infection in early pregnancy. ${ }^{15}$ Culturing amniotic fluid for virus is rarely used as the method is insensitive and takes many weeks to produce a result. ${ }^{16}$ The recent development of RNA probes for virus detection should improve the prospect for antenatal diagnosis. If used with the polymerase chain reaction this method is both rapid and highly sensitive and should reliably detect virus if present in amniotic fluid or chorionic villus samples. Experience using these techniques to diagnose intrauterine rubella infection is limited, ${ }^{17}$ and controlled studies to validate such methods are required before they can be used with confidence.

For the paediatrician, the main implication of congenital rubella resulting from reinfection is that the diagnosis should be considered in any infant with compatible symptoms irrespective of a maternal history of rubella immunity before pregnancy. Confirmation of the diagnosis in children who present late with sensorineural deafness as their only defect poses a problem as rubella specific IgM antibody rarely persists after 6 months of age. Persistence of IgG antibody after the first year of life could indicate congenital infection, but is also consistent with an acquired infection, or vaccination if the child has received the measles-mumpsrubella vaccine. Under these circumstances examination of the child's cell mediated immune response to rubella antigen can be a useful diagnostic aid. ${ }^{18}$ If rubella antibody is detected but without a cell mediated immune response in a young child then this is indicative of congenital rubella. Further information about this diagnostic test, or the use of RNA probes for antenatal diagnosis, can be obtained from the virology department of St Thomas's hospital.

Public Health Laboratory Service,

ELIZABETH MILLER

Communicable Disease

London NW9 $5 E Q$

1 Miller E, Cradock-Watson JE, Pollock TM. Consequences of confirmed maternal rubella at successive stages of pregnancy. Lancet 1982;ii:781-4.

2 Munro ND, Sheppard SS, Smithels RW, Holzel H, Jones G. Temporal relations between maternal rubella and congenital defects. Lancet 1987;ii: 201-4.

3 Peckham CS. Congenital rubella in the United Kingdom before 1970: the prevaccine era. Rev Infect Dis 1985;7:11-6.

4 Miller CL, Miller E, Waight PA. Rubella susceptibility and the continuing risk of infection in pregnancy. Br Med $\mathcal{F} 1987 ; 294: 1277-8$.

5 Noah ND, Fowles SE. Immunity to rubella in women of childbearing age in the United Kingdom. $B r$ Med $\mathcal{F} 1988 ; 297: 1301-4$.

6 Best JM, Banatvala JE, Morgan-Capner P, Miller E. Fetal infection after maternal reinfection with rubella: criteria for defining reinfection. $\mathrm{Br} M$ Med $\mathcal{J}$
mat 1989;299:773-5.

7 Gilbert J, Kudesia G. Fetal infection after maternal reinfection with rubella. Br Med f 1989;299:1217

8 Das BD, Lakhani P, Kurtz JB, et al. Congenital rubella after previous maternal immunity. Arch Dis Child 1990;65:545-6.

9 Morgan-Capner P. Does rubella reinfection matter? In: Mortimer PP, ed. Public health virology. London: Public Health Laboratory Service, 1986: $50-62$.

10 Chang T-W, DesRosiers S, Weinstein L. Clinical and serologic studies of an outbreak of rubella in a vaccinated population. $N$ Engl f Med 1970;283: 246-8.

11 Horstmann DM, Liebhaber H, Le Bouvier GL, Rosenberg DA, Halstead SB. Rubella: reinfection of vaccinated and naturally immune persons exposed in an epidemic. $N$ Engl $\mathcal{f}$ Med 1970;283:771-8.

12 O'Shea S, Best JM, Banatvala JE. Viraemia, virus excretion and antibody responses after challenge in volunteers with low levels of antibody to rubella responses after challenge in volunteers

13 Cradock-Watson JE, Ridehalgh MKS, Anderson MJ, Pattison JR Outcome of asymptomatic infection with rubella virus in pregnancy. Fournal of of asymptomatic infection with rube
Hygiene (Cambridge) 1981;87:147-54.

14 Morgan-Capner P, Hodgson J, Hambling $\mathrm{MH}$, et al. Detection of rubellaspecific IgM in subclinical rubella reinfection in pregnancy. Lancet 1985;i: $244-6$.

15 Enders G, Jonatha W. Prenatal diagnosis of intrauterine rubella. Infection 1987;15:162-4.

16 Hayes K, Lunt R, Leydon J. Experience with prenatal diagnosis of fetal rubella infection by amniocentesis. Isr f Med Sci 1983;19:1034.

17 Terry GM, Ho-Terry L, Warren RC, Rodeck CH, Cohen A, Rees KR. First trimester prenatal diagnosis of congenital rubella: a laboratory investigation. $\mathrm{Br}$ Med $\mathcal{F}$ 1986;292:930-3.

18 Hosking CS, Pyman C, Wilkins B. The nerve deaf child-intrauterine rubella or not? Arch Dis Child 1983;58:327-9. 